\title{
Aplikasi Peringatan Dini Cuaca Menggunakan Running Text Berbasis Android
}

\author{
Suherman ${ }^{1}$, Elida Pane $^{2}$, Indri Sulistianingsih ${ }^{3}$ \\ Program Studi Teknik Komputer, Fakultas Sains dan Teknologi ${ }^{1,2}$ \\ Program Studi Sistem Komputer, Fakultas Sains dan Teknologi ${ }^{3}$ \\ Universitas Pembangunan Panca Budi1,2,3 \\ suherman@dosen.pancabudi.ac.id 1, arseelida@gmail.com², indie@pancabudi.ac.id ${ }^{3}$
}

\begin{tabular}{l} 
Article Info \\
\hline History : \\
Dikirim 07 Agustus 2018 \\
Direvisi 07 September 2018 \\
Diterima 25 Februari 2019 \\
\hline
\end{tabular}

\section{Kata Kunci :}

Android

Early Warning Weather

Running Text

Wireless

\begin{abstract}
Abstrak
Informasi tentang perannya sangat besar untuk kehidupan di berbagai bidang, seperti politik, ekonomi, sosial, budaya, pertahanan dan sebagainya. Dalam kehidupan manusia, teknologi informasi berfungsi untuk memenuhi sebagian besar kebutuhan manusia. Teknologi juga digunakan untuk menyampaikan informasi di tempat-tempat umum terutama informasi yang disampaikan dan ditampilkan setiap saat selalu berubah sehingga informasi akan lebih efektif jika informasi disajikan dalam bentuk papan teks yang sedang berjalan. Menulis teks yang berjalan yang dikirim ke papan teks yang sedang berjalan saat ini masih bergantung pada perangkat koneksi USB (universal serial bus) baik dengan perangkat keyboard dan flashdisk yang mengharuskan pengguna untuk melakukan kontak fisik dengan papan teks yang sedang berjalan. Ini tentu saja dianggap tidak ramah pengguna kepada pengguna jika papan teks yang sedang berjalan berada di tempat yang sulit dijangkau. Dengan perkembangan teknologi nirkabel atau jaringan yang dapat membantu komunikasi nirkabel dan kolaborasi smartphone Android dapat memudahkan pengguna dalam mengirimkan informasi, terutama informasi tentang cuaca peringatan dini yang selalu diperbarui. Dalam penelitian ini penulis membuat aplikasi yang menjalankan teks yang dapat diperbarui menggunakan smartphone Android dengan kontrol mikrokontroler. Hasil pengujian menunjukkan bahwa alat ini dapat menjadi solusi alternatif untuk memperbarui informasi menjadi teks yang berjalan yang dapat dengan mudah beroperasi hingga jarak lebih dari 50 meter dan dapat berfungsi dari depan atau belakang teks yang sedang berjalan.
\end{abstract}

(C) This work is licensed under a Creative Commons AttributionShareAlike 4.0 International License.

\footnotetext{
Koresponden:

Indri Suliastianingsih, Program Studi Teknik Komputer, Fakultas Sains dan Teknologi

Universitas Pembangunan Panca Budi,

Jalan Gatot Subroto KM. 4.5, Medan, Indonesia, 20122

Email :indie@pancabudi.ac.id
}

\section{PENDAHULUAN}

Balai Besar Meteorologi Klimatologi dan Geofisika Wilayah I Medan adalah salah satu Instansi Pemerintah sesuai surat Keputusan Kepala Badan Meteorologi Klimatologi dan Geofisiaka Kep.005 Tahun 2004 bertanggung jawab dalam pengolahan data, analisa dan prakiraan cuaca serta 
pelayanan informasi dan jasa meteorologi klimatologi kualitas udara dan geofisika adapun dalam hal penyampaian informasi cuaca khususnya Informasi peringatan dini cuaca, Balai Besar Meteorologi Klimatologi dan Geofisika menyampaikan Informasi masih melalui web bmkg.go.id, email,sms, swasta dan televisi pemerintah atau pun swasta, ataupun ke masyarakat tertentu.[1][2] Berdasarkan latar belakang diatas penulis akan penulis akan membuat suatu aplikasi atau menambah sistim informasi peringatan dini cuaca dengan menggunakan running text berbasis android yang bisa di tempatkan di tempat tempat umum seperti pusat perbelanjaan di persimpangan jalan, ataupun di tempat tempat keramaian yang mudah di lihat langsung oleh masyarakat. Adapun tujuan dan manfaat penelitian ini adalah membantu masyarakat untuk mendapatkan informasi tentang kejadian cuaca dari running text, dan manfaatnya adalah untuk mengurangi resiko kejadian whatsApp yang disampaikan ke instansi pemerintah maupun cuaca dari running text, dan manfaatnya adalah untuk mengurangi resiko kejadian bencana yang diakibatkan oleh faktor cuaca seperti banjir, angin kencang, longsor, petir, kebakaran hutan dan lain-lain.

\section{METODE PENELITIAN}

Pada bagian ini dijelaskan tentang Metode Penelitian (bisa meliputi analisa, arsitektur, metode yang dipakai untuk menyelesaikan masalah, implementasi), Pada setiap paragraph bisa terdiri dari beberapa subparagraph yang ditunjukkan section berikut ini [3].

\subsection{Pengumpulan Data}

Lokasi penelitian ini dilakukan pada kantor Balai Besar Meteorologi Klimatologi dan Geofisika Wilayah I Medan yang beralamat di Jalan Ngumban Surbakti No. 15 Sempakata Medan, metode pengumpulan data yang digunakan adalah wawancara adalah dengan megajukan pertanyaan secara langsung kepada objek yang diteliti. yaitu tentang analisa dan cara pengiriman data informasi peringatan dini cuaca kepada masyarakat. Adapun wawancara yang dilakukan oleh penulis dalam penelitian ini adalah dengan melakukan wawancara langsung kepada Bapak Syahnan sebagai Kepala Bidang Data Dan Informasi di Kantor Balai Besar Meteorologi Klimatologi dan Geofisiak Wilayah I Medan.

\subsection{Running text}

Running text adalah sebuah papan informasi yang di gunakan untuk menyampaikan informasi apa saja dalam bentuk tulisan berjalan dan bisa juga di sebut sebagai let-let yang disambung dari rangkaian menjadi deretan let ataupun dapat berupa dot matrix. Dot matrix merupakan deretan let yang membentuk array dalam jumlah kolom dan baris tertentu, sehinngga titik-titik yang menyala dapat membentuk suatu karekter seperti angka, huruf, tanda baca dan sebagainya, papan tersebut sering digunakan sebagai sarana untuk menginformasikan suatu produk yang biasa ditempatkan ditempat tempat keramaian seperti informasi Peringatan dini cuaca.[3][4]

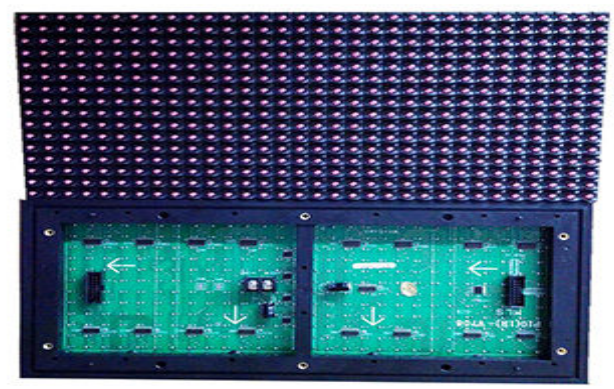

Gambar 1. Modul Outdoor P10

\subsection{Mikrocontroller}

Mikrocontroller adalah sebuah alat pengendali berikuran mikri yang dikemas dalam bentuk chip IC. Mikrocontroller umumnya terdiri dari CPU (Central Processing Unit) yang menjalankan instruksi program, memori RAM (Random Acces Memory) dan ROM (Read Only Memory).[5] 


\subsection{Modul Wifi ESP}

Modul Wifi ESP adalah merupakan modul wifi yang berfungsi sebagai perangkat tambahan mikrokontroler seperti Arduino agar dapat terhubung langsung dengan wifi dan membuat koneksi TCP/IP. Modul ini membutuhkan daya sekitar 3.3v dengan memiliki tiga mode wifi yaitu Station, Access Point dan Both (Keduanya). Modul ini juga dilengkapi dengan prosesor, memori dan GPIO dimana jumlah pin bergantung dengan jenis ESP yang kita gunakan. Sehingga modul ini bisa berdiri sendiri tanpa menggunakan mikrokontroler apapun karena sudah memiliki perlengkapan layaknya mikrokontroller. [6]

\subsection{Alur Kerja Sistem}

Berikut ini adalah bagan alir dan bagan analisis penggunaan aplikasi dan kerangka kerja sistem yang dibangun menggunakan running text berbasis Android.

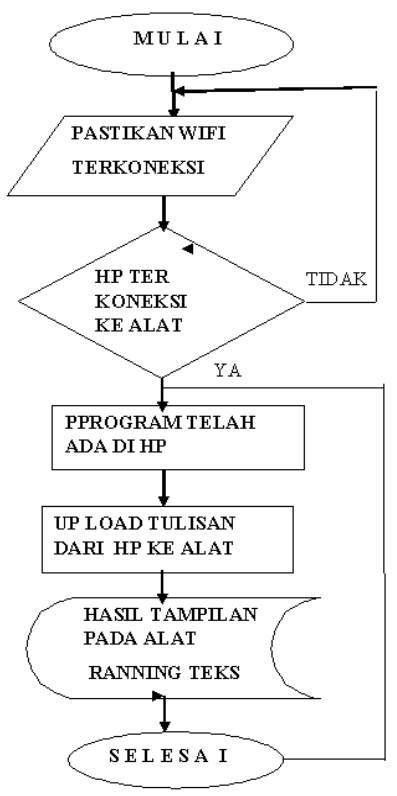

Gambar 2. Flowchart Running text

Bagan alir atau flowchart diatas mejelaskan urutan langkah kerja penggunaan sistem yang dijalankan dengan menggunakan ponsel yg terkoneksi dengan jaringan wifi dan menjalankan aplikasi yang telah terinstal pada ponsel tersebut sampai pada proses upload data untuk menjalankan running text.

Selanjutnya pada gambar 3 dibawah ini menggambarkan kerangka kerja sistem peringatan dini cuaca yang dibedakan menjadi beberapa bagian mulai dari observasi, komunikasi, pengolahan dan diseminasi. 


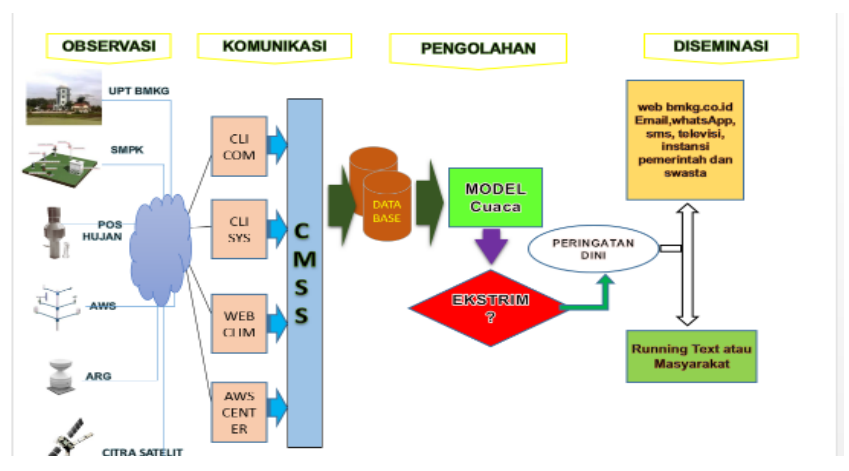

Gambar 3. Analisa Sistem Peringatan Dini Cuaca

\section{HASIL DAN PEMBAHASAN}

Merancang sistem aplikasi dari alat, blok diagram flowchart dan software yang menggambarkan sitematika alat secara keseluruhan yang terdiri dari komponen yang digunakan. Siapkan 3 pcs modul let matrix p10, kemudian susun seperti gambar 4 dibawah ini.

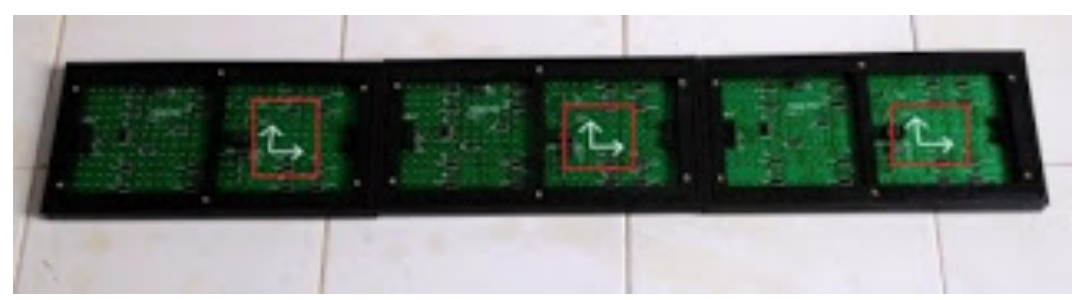

Gambar 4. Rangkaian alat running text

Hubungkan kabel power let di antara modul let metrix bisa menggunakan kabel merah hitam. Pertikan termin 5V terhubung ke termin 5V lainnya dan termin GND terhubung ke termin GND pada modul let matrix lainnya.

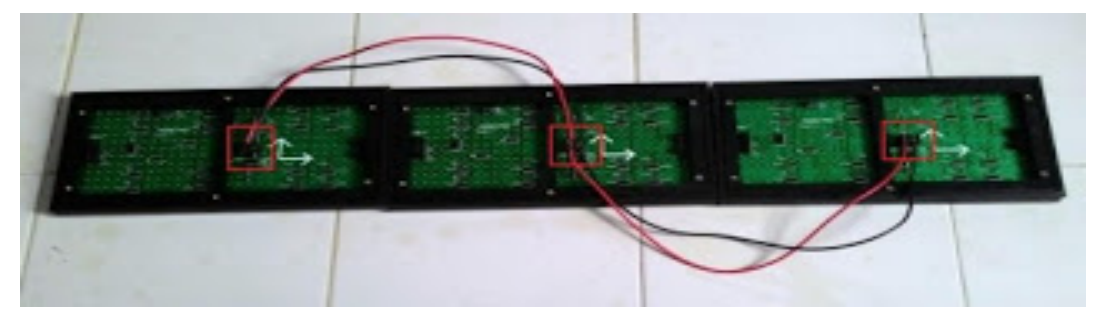

Gambar 5. Rangkaian alat running text

Hubungkan kabel data untuk menyambung koneksi antara modul let matrix hubungkan juga koneksi power 5 volt dari power supply ke kontroler running text kaler XU2 dan ke modul let matrix p10, pastikan sambungan kabel tidak terbalik. Sambungan kontroler dan let matrix harus berada pada sebelah kiri, dan detailnya dapat dilihat pada gambar di bawah ini 


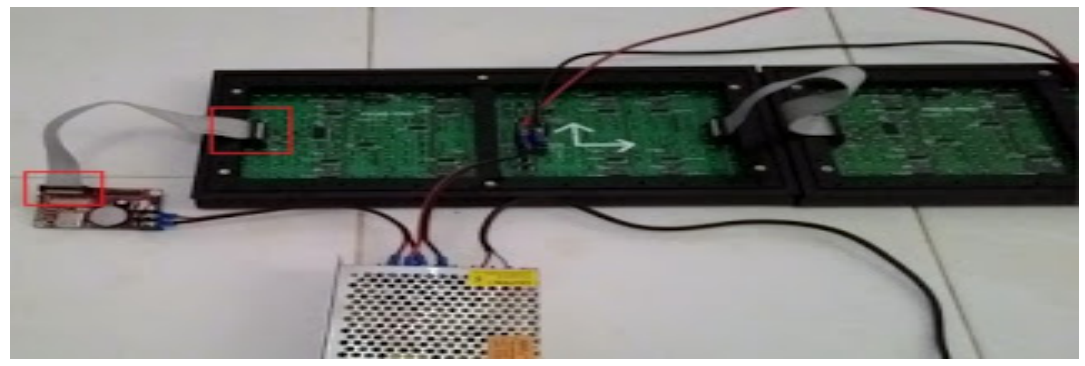

Gambar 6. Rangkaian alat running text

Setelah semua Kabel terpasang seperti gambar di atas, nyalakan power supply untuk memastikan power sudah terhubung ke kontroler running text dan ke modul let matrix, jika power sudah masuk. Jika koneksi telah tersambung semua nya, balikkan arah let matrix agar sisi let berada di atas dan let matrix siap digunakan.

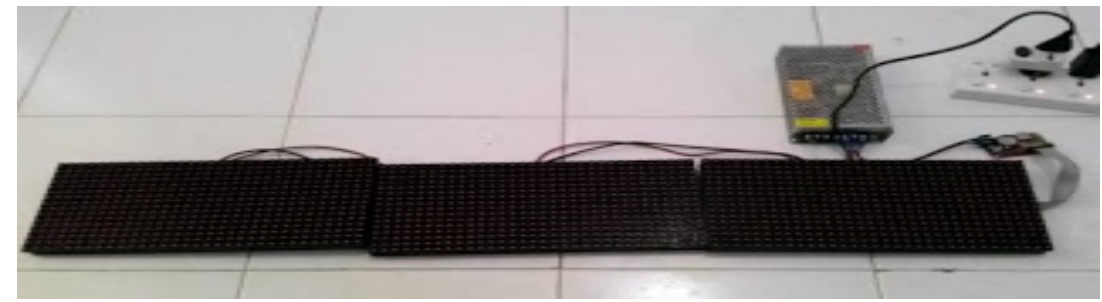

Gambar 7. Rangkaian alat running text

Untuk setting Kontroller dengan Android harus instal dulu Power LED di android, kemudian koneksikan wifi android dengan wifi kontroller TR-SW anda kemudian buka aplikasi Power Led di Android akan muncul tampilan Power Let di Andoid adalah sebagai berikut.

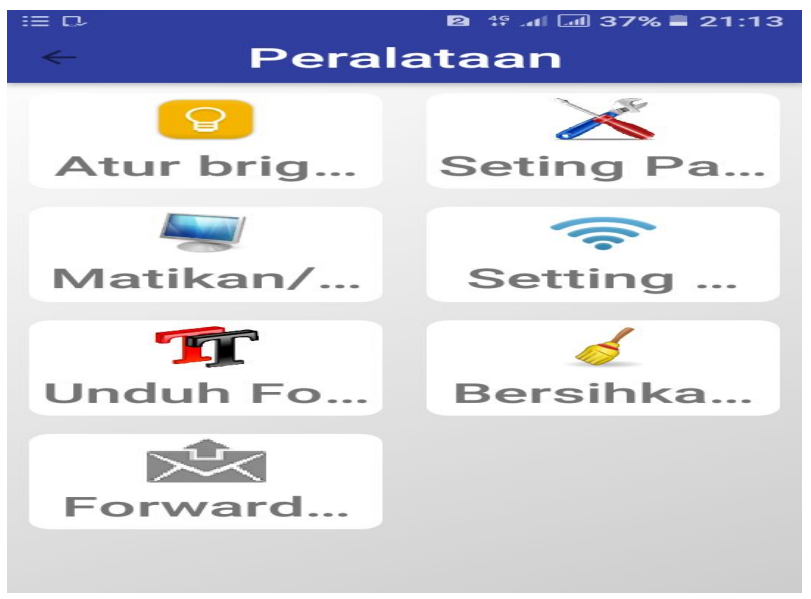

Gambar 8. Menu Peralatan Program Let Matrix

Selanjutnya kemudahan dalam mengatur Program Let Matrix pada Menu berikut ini, kita dapat mengatur text dengan mudah secara visual menggunakan form seperti dibawah : 


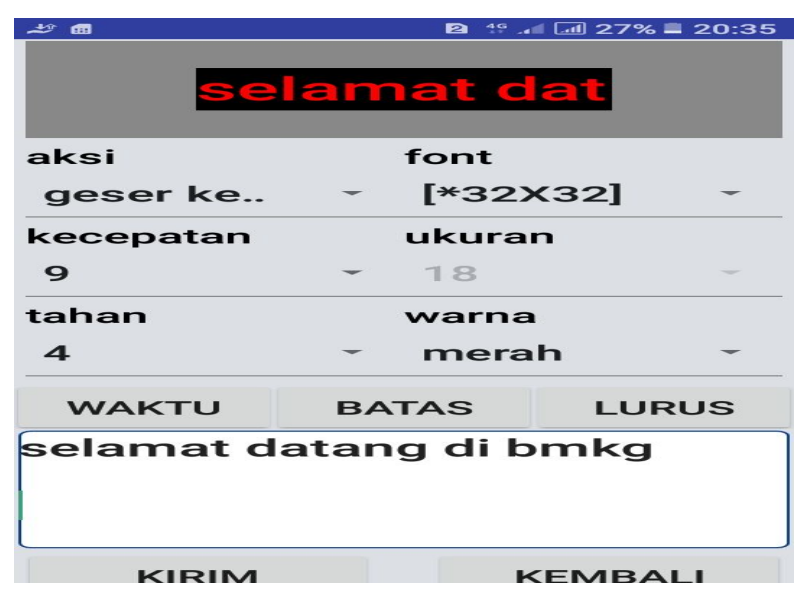

Gambar 9. Menu Edit Program Let Matrix

Blok diagram dibawah ini menggambarkan alur sistem pada ponsel android ke alat-alat hingga ditampilkan ke running text.

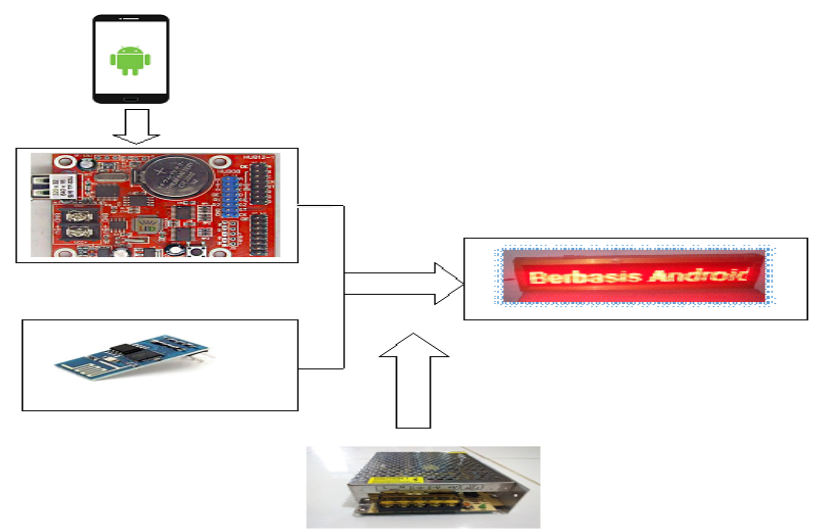

Gambar 10. Blok Diagram Alat Running text

\section{Pengujian}

Pengujian dilakukan untuk mengetahui apakah modul Aplikasi running text telah bekerja dengan benar atau tidak, sebelum dihubungkan dengan modul Wifi_esp maka dilakukan pengujian rangkaian Aplikasi running text yang telah dibuat. Pengujian dilakukan dengan cara memasukkan kata atau kalimat pada program Aplikasi Android kemudian akan tampil pada running text.

Tabel 1. Pengujian Modul Alat Running text

\begin{tabular}{cc}
\hline Masukkan dari android kata & Kata tampil pada running text \\
\hline Selamat dating di BMKG & Selamat dating di BMKG \\
\hline Aplikasi Sistem Informasi & Aplikasi Sistem Informasi \\
\hline Peringatan Dini Cuaca & Peringatan Dini Cuaca \\
\hline Berbasis Android & Berbasis Android \\
\hline
\end{tabular}


Gambar berikut adalah contoh keberhasilan Aplikasi atau sistem menampilkan text pada aplikasi dan running text sebagai uji coba sistem berjalan sesuai dengan fungsi sebagai peringatan cuaca dini.

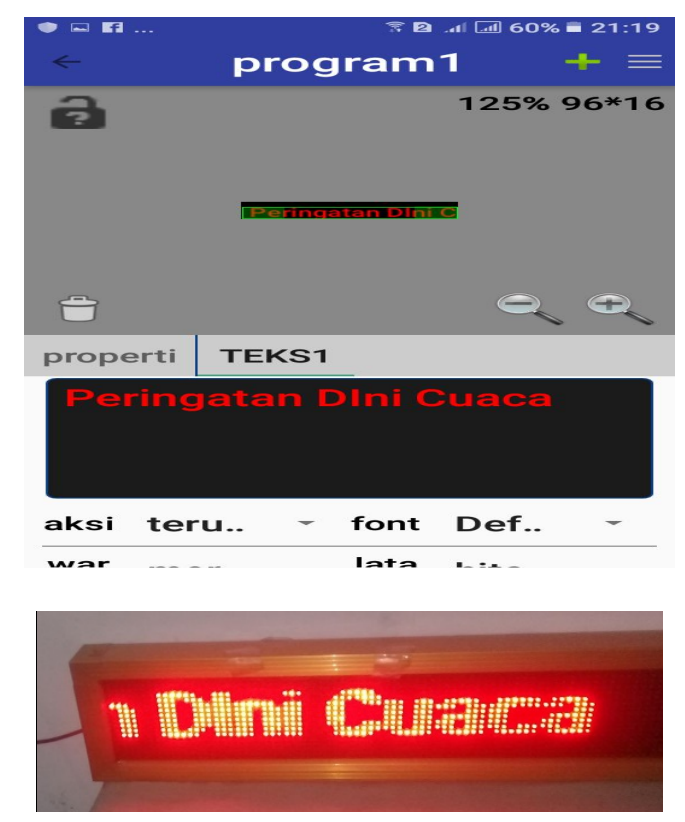

Gambar 11. Pengujian Modul Alat Running text

Pengujian jangkauan modul wifi -esp dengan cara alat diletakkan diatas dengan ketinggian 5 meter dari permukaan tanah, penguran jangkauan dilakukan dari depan dan belakang alat seperti tampak paga gambar.

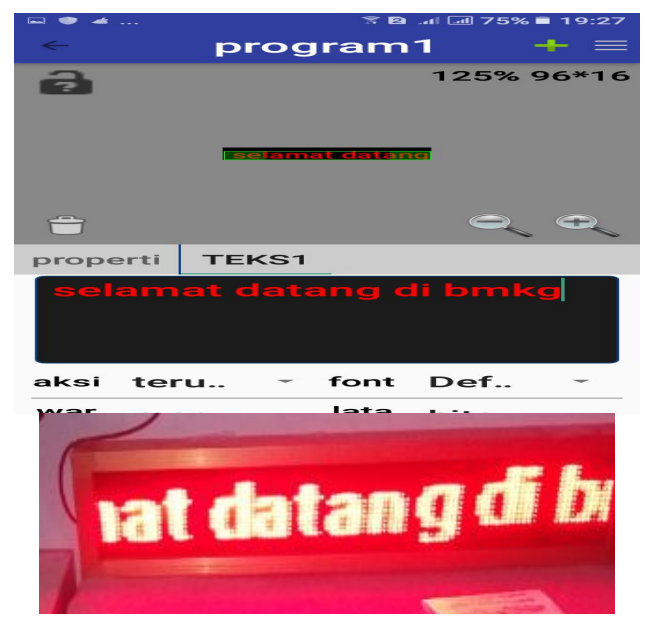

Gambar 14. Pengujian Modul Alat Running text

Berikut tabel hasil pengujian jarak jangkauan running text dengan aplikasi sesuai dengan hasil uji coba yang telah dilakukan. 
Tabel 2. Hasil Pengujian Jarak Jangkauan

\begin{tabular}{cccc}
\hline Jarak (Meter) & Status wifi - esp & $\begin{array}{c}\text { Pengujian Dari Depan } \\
\text { Alat }\end{array}$ & $\begin{array}{c}\text { Pengujian Dari } \\
\text { Belakang Alat }\end{array}$ \\
\hline 5 & Terhubung & Data ter update & Data ter update \\
\hline 10 & Terhubung & Data ter update & Data ter update \\
\hline 15 & Terhubung & Data ter update & Data ter update \\
\hline 20 & Terhubung & Data ter update & Data ter update \\
\hline 25 & Terhubung & Data ter update & Data ter update \\
\hline 30 & Terhubung & Data ter update & Data ter update \\
\hline 35 & Terhubung & Data ter update & Data ter update \\
\hline 40 & Terhubung & Data ter update & Data ter update \\
\hline 45 & Terhubung & Data ter update & Data ter update \\
\hline
\end{tabular}

\section{KESIMPULAN}

LED Matrix yang menyampaikan informasi dalam bentuk Running text menggunakan mikrokontroler (Arduino) dan Android telah sesuai dengan yang dirancang.

WiFi-esp berhasil sebagai jalur komunikasi Arduino pengendali LED Matrix dengan Android untuk merubah informasi yang ditampilkan LED Matrix, sehingga penggantian informasi dari android lebih efisien.

Running text dapat di kontrol dengan jarak kurang lebih 50 meter dari tempat penetakan Alat, jadi sangat sesuai di gunakan sebagai alternatif tambahan untuk alat atau sarana dalam memberikan informasi cuaca khusnya informasi peringatan dini cuaca karena cara peng update tan nya sangat mudah dan running text nya juga bisa di tempat kan di tempat yang sesuai dengan yang di inginkan.

\section{DAFTAR PUSTAKA}

[1] BMKG, Keputusan No. 005 Tugas dan Fungsi Balai Besar Meteorologi Klimatologi dan Geofisika. 2004.

[2] BMKG, "Pedoman Pelayanan Peringatan Dini Tsunami InaTEWS," Edisi Kedu., Penerbit Badan Meteorologi Klimatologi Dan Geofisika, 2012.

[3] I. R. J. Anton Wasid Nugroho, Dedi Triyanto, "Aplikasi Running text dengan update Informasi.," J. Coding Sist. Komput. Untan, 2015.

[4] I. F. Samijayani, Octarina Nur, Rahsanjani, "Perancangan Sistem Penulisan Text pada Running text Menggunakan SMS," Univ. Al Azhar Indones., 2014.

[5] H. Santoso, "Panduan Praktis Belajar Arduino untuk Pemula dan Rangkaian Source Code Sensor Teori Pendukung." Brawijaya Malang, 2016.

[6] A. Kadir, Pemrograman Arduino dan Android menggunakan App Inventor. Elex Media Komputindo, 2014. 